\title{
Representações discursivas da violência contra a mulher e a orientação argumentativa em textos de inquérito policial
}

\section{Discursive representations of violence against women and argumentative orientation in police inquiry texts}

\author{
Maria de Fátima Silva dos Santos \\ santosfatima382@gmail.com \\ Secretaria Municipal de Educação de Santa Cruz, RN \\ Maria do Socorro Oliveira ${ }^{* *}$ \\ msocorrooliveira67@gmail.com \\ Secretaria de Estado da Educação e da Cultura, RN
}

Resumo: Este artigo apresenta resultados de uma pesquisa sobre a representação discursiva de vítima e agressor em inquéritos policiais. Tomando por base os fundamentos teóricos da Linguística Textual, mais especificamente, a Análise Textual dos Discursos (ATD), proposta pelo linguista Jean-Michel Adam (2011), temos por objetivo analisar a construção das representações discursivas de vítima e a função dessas representações para a orientação argumentativa pretendida em textos de inquérito policial. Seguindo princípios da pesquisa documental, de base qualitativa, exploramos um corpus constituído por nove inquéritos policiais relacionados a crimes de violência praticados contra a mulher. Os resultados, considerados na situação analisada, evidenciam que a construção das representações de vítima, em textos de inquéritos policiais, cumpre uma função argumentativa relacionada à intencionalidade do enunciador e aponta a relevância da compreensão do processo de composição dessas representações para a construção dos sentidos, de acordo com a perspectiva dos sujeitos enunciadores.

Palavras-chave: Análise Textual dos Discursos. Argumentação. Intencionalidade argumentativa. Representação discursiva. Violência.

\begin{abstract}
This article presents results of a research on the discursive representation of victims and offenders in police investigations. Based on the theoretical foundations of Textual Linguistics, more specifically, Textual Discourse Analysis (TDA), proposed by linguist Jean-Michel Adam (2011), we aim to analyze the construction of the discursive representations of victims and the function of these representations for the required argumentative orientation in police investigation reports. Following principles of a qualitative based documentary research, we investigate a corpus comprised of nine police investigation reports related to crimes of violence committed against women. The results show that the construction of victim representation in police investigation reports plays an argumentative role related to the intentionality of the enunciator and points out the importance of understanding the process of
\end{abstract}

\footnotetext{
"Doutora em Estudos da Linguagem pela Universidade Federal do Rio Grande do Norte (UFRN)

${ }^{* *}$ Doutora em Estudos da Linguagem pela Universidade Federal do Rio Grande do Norte (UFRN)
} 
composition of these representations for the construction of the senses, according to the perspective of the enunciating subjects.

Keywords: Textual Discourse Analysis. Argumentation. Argumentative intentionality. Discursive representation. Violence.

\section{Introdução}

Discutimos, neste artigo, aspectos teóricos relativos à representação discursiva e à orientação argumentativa, levando em consideração a intencionalidade $^{1}$ do discurso. Para tanto, fundamentamo-nos nos postulados de Adam (2011), Koch (2011, 2010), dentre outros. Partimos do pressuposto de que a construção de uma determinada representação discursiva revela a intencionalidade do escritor e orienta argumentativamente o leitor na construção dos sentidos pretendidos no texto. A intencionalidade refere-se à forma como os sujeitos utilizam a linguagem para influenciar no comportamento do outro, ou seja, para cumprir um determinado propósito comunicativo.

Os documentos que constituem o corpus de nossa pesquisa foram coletados na Delegacia Especializada de Amparo à Mulher (DEAM - Zona Sul), na cidade de Natal, Estado do Rio Grande do Norte. De um modo geral, o atendimento às mulheres nessa delegacia ocorre da seguinte forma: a denunciante é recebida por um agente policial que ouve a queixa e a registra no boletim de ocorrência. A fim de evitar maior constrangimento para a denunciante, o atendimento é feito em uma sala reservada (diferentemente das delegacias comuns, em que o registro é feito em local aberto). Conforme o caso, a vítima é encaminhada para realizar exame de corpo de delito no Instituto Técnico da Polícia Civil, para as assistências jurídicas gratuitas ou para outros serviços relacionados com a denúncia da vítima.

Nos casos de prisão em flagrante, em que o acusado é conduzido à delegacia pela polícia militar, é lavrado o auto de prisão do acusado. Caso contrário, se a vítima faz a denúncia sem que tenha sido feito o auto de prisão em flagrante, ao final do registro da ocorrência, é marcada uma audiência preliminar com a delegada ou a assistente social, em que serão ouvidos o acusado e a vítima, a fim de que seja estabelecido um possível acordo entre as partes ou um encaminhamento para a representação criminal.

\footnotetext{
${ }^{1}$ A intencionalidade é um dos princípios de textualidade, apresentado por Beaugrande (1997), que define as escolhas que o autor faz, ao produzir seu texto, e que orienta o leitor na construção de sentidos do texto.
} 
A depender do tipo de crime, a representação criminal poderá ser efetivada de duas formas. Nas infrações penais de menor potencial ofensivo (com pena máxima de até dois anos), a vítima é encaminhada para registrar o Termo Circunstanciado de Ocorrência (TCO) no cartório da própria delegacia. Trata-se de um instrumento criado para dar agilidade à justiça. É como um boletim de ocorrência, porém mais detalhado, incluindo identificação e depoimento do autor, da vítima e das testemunhas. Com o TCO concluído, a delegacia encaminha-o para o Juizado Especial Criminal, terminando assim a sua participação no processo.

Nos casos de crimes considerados pela lei de maior gravidade, a delegacia inicia o inquérito policial, no qual se ouvem as partes (vítima e acusado), as testemunhas, coletam-se as provas e monta-se toda a peça para ser levada ao Judiciário. O inquérito é concluído com o relatório final da delegada e o seu encaminhamento para o Poder Judiciário, terminando assim o trabalho da delegacia no caso.

Em sua estrutura, este artigo encontra-se assim organizado: inicialmente, apresentamos a resenha de algumas pesquisas que tratam da temática da violência contra a mulher; dando prosseguimento, discutimos alguns conceitos teóricos relativos à representação discursiva e à argumentação linguística; em seguida, apresentamos a abordagem da pesquisa, com uma breve descrição do corpus, seguidos de excertos e resultados da análise das representações discursivas de vítima e da violência contra a mulher em uma amostragem de documentos de inquérito policial, pondo em foco a relação entre as representações discursivas e a orientação argumentativa do texto.

\section{A violência contra a mulher}

Entre os temas que têm ocupado o centro das reflexões sobre a violência, a questão da violência contra a mulher tem sido um dos mais recorrentes e instigantes nas pesquisas de diversos estudiosos. A título de exemplo, mencionamos os trabalhos de Pasinato (2003), Oliveira (2004) e Queiroz (2008), apenas para citar alguns.

Em sua tese de doutorado Justiça para todos: os Juizados Especiais Criminais e a violência de gênero, Pasinato (2003) realizou uma pesquisa para conhecer e avaliar o impacto das mudanças implantadas pela Lei 9.099/95, que 
criou os Juizados Especiais Criminais, em sua aplicação aos casos de violência contra a mulher. A pesquisadora analisou os registros policiais realizados em três delegacias de defesa da mulher, localizadas no Município de São Paulo, entre os anos de 1996 e 1999, especialmente os casos de violência que envolveram relações conjugais e de namoro, destacando-se aqueles em que houve mais de um registro de ocorrência pela mesma vítima contra o mesmo autor.

A pesquisadora focalizou a análise no comportamento das mulheres, assumindo que esse comportamento que se repete expressa o modo como elas incorporam em seu cotidiano um discurso sobre direitos. Para a autora, esse discurso não é assimilado de forma idêntica por todas, tendo em vista que assume nuances de classe social, etnia e faixa etária. Ao analisar as idas e vindas dessas mulheres que registraram mais de uma ocorrência nas delegacias, Pasinato (2003) argumenta que a decisão de recorrer à polícia e a capacidade legal de manifestação no decorrer do processo revelam um modo de exercício do poder exercido pelas mulheres. Com isso, a autora evidencia que o novo modelo alternativo à justiça tradicional e convencional corresponde às expectativas de algumas mulheres vítimas de violência, além de revelar outro tipo de vínculo entre gênero, conflitos e Justiça, através dos quais as mulheres se apropriam de discursos sobre direitos e violência - próprios da esfera policial-judicial, para conferir legitimidade às decisões que procuram obter.

A autora afirma, ainda, que a decisão das mulheres em procurar a polícia e, posteriormente, em manter ou não a queixa perante a justiça representa uma forma de exercício de poder dessas mulheres, revelando também que elas não pactuam com o lugar de vítimas passivas da violência. Nessa ótica, o direito de representação deve ser entendido como a capacidade legal para intervir no desenrolar dos acontecimentos, elemento fundamental para o exercício da liberdade e autodeterminação.

Para Pasinato (2003), a aplicação da lei 9.099/95 vem sendo diagnosticada como fator de discriminação e reprivatização da violência contra a mulher - isso porque as decisões obtidas nos Juizados apontavam para a privatização do conflito, assim como a ausência de respostas judiciais reforçava a velha concepção de que "em briga de marido e mulher ninguém mete a colher". Contudo, contrariando essa concepção, a autora observa que o período de implantação dos Juizados coincidiu com o crescimento no número de registros policiais registrados nas delegacias 
especializadas, sugerindo que delegacias e juizados se constituíram em importantes espaços de "fortalecimento" das mulheres em situações de violência.

Em artigo intitulado Da Delegacia de Defesa da Mulher ao Juizado Especial Criminal: significados da violência de gênero no fluxo processual, Oliveira (2004), por sua vez, aborda a violência contra a mulher na perspectiva de gênero. A autora focalizou parte relevante do sistema - o Juizado Especial Criminal, chamado de "justiça informal" -, no sentido de entender como o procedimento jurídico implantado com a Lei 9.099/95, que institui os Juizados Especiais Criminais, influencia no modo como a justiça trata a questão da violência de gênero, particularmente a agressão contra a mulher na relação conjugal.

Conforme observações de Oliveira (2004), a Lei 9.099/95 introduziu mudanças no ordenamento jurídico brasileiro seguindo o movimento de ampliação do acesso à justiça para a população, por meio da implantação da desburocratização, conciliação e aplicação de penas alternativas para os crimes de menor potencial ofensivo. A autora informa que os modelos de resolução de conflitos baseados na conciliação vêm conquistando um interesse cada vez maior no contexto jurídico brasileiro contemporâneo, e o juizado especial civil e criminal é, precisamente, o exemplo mais evidente da forma como esse interesse foi institucionalizado. Na pesquisa, Oliveira (2004) analisa o modo como essa conciliação, mínima intervenção penal, abolicionismo penal ou despenalização, que sustenta os juizados, foi recepcionada pela justiça brasileira e os efeitos que vem produzindo no julgamento da violência de gênero.

Oliveira toma como base o Juizado Especial Criminal (JECrim) e a Delegacia de Defesa da Mulher (DDM). Ela defende a ideia de que há uma mudança dos significados do crime e de seus sujeitos no fluxo da justiça - da DDM ao JECrim quando a violência de gênero está em jogo, de acordo com a lógica própria de cada uma dessas instituições. Segundo essa autora, enquanto a DDM politizou a justiça pois é fruto de movimentos políticos de reinvindicações feministas - no sentido de criminalização da violência contra a mulher, possibilitando a entrada desse conflito no sistema de justiça, o JECrim tornou o conflito invisível no Judiciário, reprivatizando-o.

Conforme observações de Oliveira (2004), a informalização dos procedimentos judiciais, a partir da Lei 9.099/95, criada com o intuito de maximizar a eficiência e, sobretudo, ampliar o acesso à justiça, acabou por despolitizar o esforço 
do movimento social em tornar visível o abuso cometido contra mulheres pelo simples fato de serem mulheres. De um lado, as delegacias de defesa da mulher, criadas nos anos 80 , foram uma das faces mais visíveis da politização da justiça na garantia dos direitos da mulher e uma forma de pressionar o sistema de justiça na criminalização de assuntos tidos como questões privadas. Por outro lado, a criação dos Juizados Especiais Criminais permitiu a chegada desse conflito ao Judiciário, pois muitas das vezes não transpunham a etapa policial. Contudo, ao acelerar a retirada dos conflitos considerados de "menor potencial ofensivo" do âmbito penal, acabou por tornar invisível a violência de gênero.

A pesquisadora enfatiza, ainda, que embora a criação da lei intencionasse mudar o sistema de justiça no sentido de ampliar o acesso da população à justiça, a invisibilização do conflito de gênero foi uma consequência inesperada. Para ela, o problema não está na informalização provocada pela Lei 9.099/95, mas, sobretudo, em uma informalização que, na prática, acabou por enfatizar apenas a celeridade, reforçando e contribuindo para a permanência das desigualdades de poder nas relações de gênero.

Na concepção de Oliveira (2004), a categoria gênero recorta a sociedade a partir dos papéis sexuais socialmente definidos e implica, sobretudo, na recusa de qualquer resquício de determinação biológica ou natural dessa dominação, reconhecendo a configuração histórica e cultural, portanto, política, das relações entre os sexos. Esse entendimento torna possível analisar a permanência dos significados da violência de gênero no fluxo processual como práticas de violência contra a mulher na sociedade. Por isso, Oliveira (2004) opta pela definição de violência de gênero, pois, segundo ela, no termo "gênero" estão implícitas a noção relacional e de assimetria de poder numa relação.

Nessa mesma perspectiva, em Não se rima amor e dor: cenas cotidianas de violência contra a mulher, Queiroz (2008), por sua vez, analisa as representações sociais que as mulheres, vítimas de violência conjugal, pertencentes às classes populares, constroem sobre a violência sofrida. A obra, produzida originalmente em formato de tese de doutorado em Serviço Social, encontra-se estruturada em seis capítulos.

No primeiro capítulo, A violência como um complexo campo teóricometodológico de pesquisa, Queiroz apresenta as principais abordagens sociológicas explicativas da violência: a vertente funcionalista, a estrutural-marxista e a da 
microssociologia ou micropolítica da violência. No segundo capítulo, O poder como elemento de mediação das relações sociais de gênero, a autora centraliza a discussão na perspectiva da "microfísica do poder". Nessa perspectiva, o poder é situado como algo que está além do Estado, perpassando todas as instituições e relações sociais estabelecidas. Na sequência, trata das relações sociais de gênero entendidas como relações sociais de poder.

No terceiro capítulo, As representações sociais como forma de conhecimento da realidade, a autora perpassa pelas diferentes abordagens teóricas acerca das representações sociais. No quarto capítulo, apresenta os procedimentos metodológicos utilizados para a operacionalização dos objetivos da pesquisa, justifica as escolhas dos diversos procedimentos, o universo da pesquisa, os recortes e a produção dos dados, dentre outros recursos utilizados. No quinto capítulo, $\mathrm{O}$ universo de significados simbólicos que permeia a violência conjugal, Queiroz (2008) analisa as representações sociais voltadas para os temas "ser mulher", "ser homem", "as relações de gênero", "família" e "casamento". Com isso, a autora objetiva trazer à tona alguns elementos que possam elucidar a dominação masculina presente na relação conjugal, expressa, dentre outras formas, na violência contra a mulher. Finalmente, no sexto capítulo, A violência contra a mulher: modos de ver, sentir e reagir das mulheres, a autora descreve as representações sociais sobre a violência contra a mulher, os fatores que contribuem para essa violência, bem como, os argumentos justificadores da permanência das mulheres nas relações violentas.

\section{A noção de representação discursiva}

Para Adam (2011, p. 113), "[t]oda proposição enunciada possui um valor descritivo. A atividade discursiva de referência constrói, semanticamente, uma representação, um objeto de discurso comunicável". Em outras palavras, uma representação semântica do discurso constrói-se, minimamente, a partir de "[...] um tema ou objeto de discurso posto e o desenvolvimento de uma predicação a seu respeito. A forma mais simples é a estrutura que associa um sintagma nominal a um sintagma verbal" (ADAM, 2011, p. 113). Semanticamente, uma proposição pode, também, reduzir-se a um nome e a um adjetivo. 
A esse respeito, Rodrigues, Passeggi e Silva Neto (2010, p. 173), em consonância com Adam (2011), observam que "[...] toda proposição, na condição de 'microuniverso semântico', constitui uma representação discursiva mínima”. Nessa perspectiva, segundo esses autores, "A dimensão referencial da proposição apresenta uma certa 'imagem' do(s) referente(s) discursivo(s), posto que cada expressão utilizada categoriza ou perspectiva o referente de uma certa maneira" (p. 173). Assim, nessa perspectiva, a linguagem faz referência e o texto passa a ser concebido como uma proposição de mundo que solicita do sujeito interpretante uma atividade semelhante, mas não simétrica, de (re)construção dessa proposição de (pequeno) mundo, ou representação discursiva.

Desse modo, "[t]odo texto constrói, com maior ou menor explicitação, uma representação discursiva do seu enunciador, do seu ouvinte ou leitor e dos temas ou assuntos que são tratados." (RODRIGUES, PASSEGGI e SILVA NETO, 2010, p. 173). Assim, nessa perspectiva, pode-se afirmar que o sujeito falante sabe que a língua nem sempre pode dizer tudo, e que, em certas situações, a comunicação pode ser falha, mas ele sabe, também, que isso não é suficiente para impedir a referência ao mundo, às palavras, à própria situação de enunciação e aos coenunciadores.

Ramos (2011), por sua vez, elabora um esquema no qual a representação discursiva posiciona-se em uma situação de interação em que o sujeito constrói uma imagem de si mesmo (A), do seu interlocutor (B) e do tema de seu discurso (T). Do mesmo modo, o interlocutor (B) (re)constrói uma imagem de si mesmo, do locutor (A) e do tema do seu discurso (T). Essas imagens ou representações são construídas com base nos seus objetivos e intenções, nas representações psicossociais e nos pré-construídos culturais, conforme ilustrada na Figura 1, a seguir. 
Figura 1: As representações discursivas $(\mathrm{Rd})$

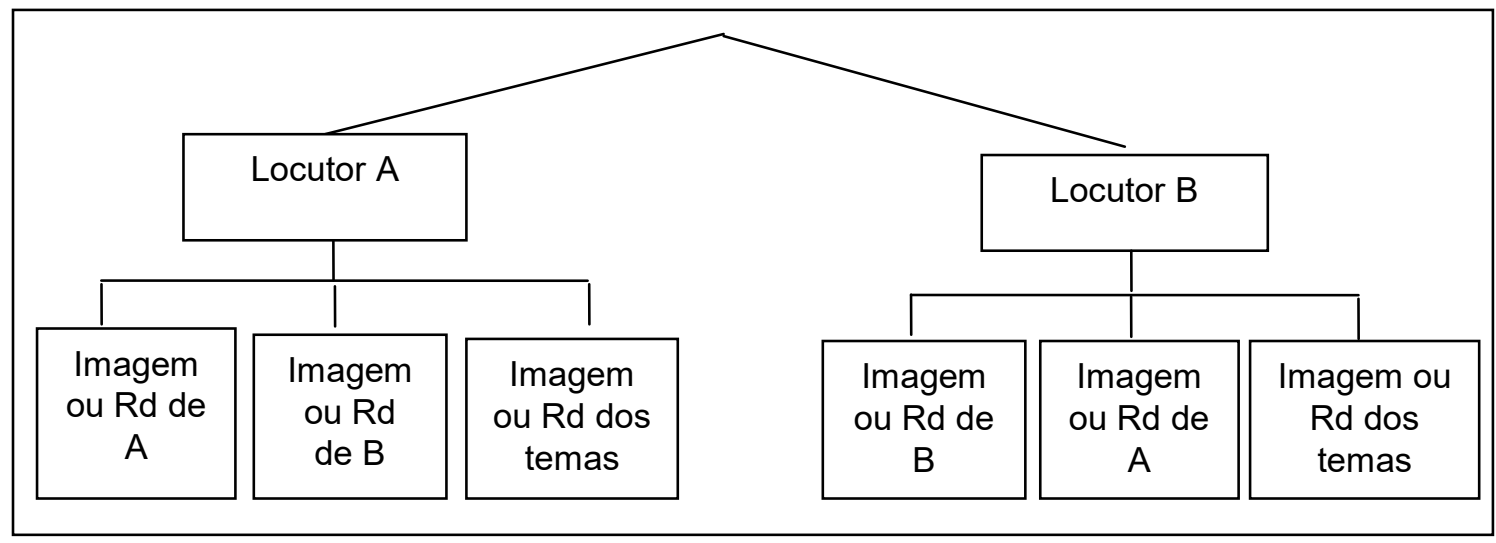

Fonte: Adaptado de Ramos (2011, p. 43)

Logo, pode-se considerar que, do ponto de vista discursivo, uma representação discursiva sugere a construção de três imagens: a imagem do locutor (A) interveniente na situação de comunicação, do tema (T) do seu discurso e do interlocutor (B) (virtual ou não) ao qual aquele se dirige.

De acordo com Amossy (2011a, p. 9), "[t]odo ato de tomar a palavra implica a construção de uma imagem de si”. Para isso, no entanto, a autora acrescenta, logo em seguida, que o locutor não precisa, necessariamente, fazer o seu autorretrato, tão pouco detalhar suas qualidades nem falar de si. Isso porque, conforme Amossy (2011a, p. 9), "[s]eu estilo, suas competências linguísticas e enciclopédicas, suas crenças implícitas são suficientes para construir uma representação de sua pessoa". Assim, o locutor efetua, em seu discurso, uma representação de si. Contudo, conforme ressalta a autora, essa representação de si não se limita a uma técnica apreendida ou a um artifício: ela se efetua, frequentemente, na interação com o outro, nas trocas verbais mais corriqueiras e mais pessoais. Na visão aristotélica, essa imagem de si é representada pela figura do ethos, em que se destaca o caráter que o orador assume em seu discurso com vistas a convencer o auditório.

\section{Argumentação linguística}

A argumentação é parte constitutiva do funcionamento discursivo. Como ser dotado de razão e de vontade, o homem, constantemente, forma juízos de valor, isto é, avalia, critica, julga. Do mesmo modo, por meio do discurso, o homem busca influenciar o comportamento do outro, a fim de compartilhar determinadas opiniões. 
Por esta razão, segundo Koch (2011), "[...] o ato de argumentar, isto é, de orientar o discurso no sentido de determinadas conclusões, constitui 0 ato linguístico fundamental, pois a todo e qualquer discurso subjaz uma ideologia, na acepção mais ampla do termo." ( $\mathrm{KOCH}, 2011$, p. 17, grifos da autora). Nesse sentido, o discurso constitui uma unidade pragmática, atividade capaz de produzir efeitos e reações.

Ao produzir um discurso, o sujeito se apropria da língua, não apenas com a finalidade de veicular mensagem ou de transmitir informações, mas, principalmente, com a intenção de influenciar as ideias, opiniões, enfim, atuar sobre o outro. Assim, o homem se apropria da linguagem para interagir socialmente, "[...] instituindo-se como EU e constituindo, ao mesmo tempo, como interlocutor, o outro, que é por sua vez constitutivo do próprio EU, por meio do jogo de representações e de imagens recíprocas que entre eles se estabelecem" (KOCH, 2011, p. 19). Nessa perspectiva, é necessário considerar a intencionalidade na produção de linguagem.

Fiorin (2015, p. 78) considera que "[...] a argumentação é uma questão de linguagem. Por isso, nela o enunciador trabalha com a pluralidade de sentidos de uma palavra, os sofismas". O autor cita como exemplo o papel argumentativo da palavra "denuncismo" em lugar de denúncia utilizada no campo político. "Enquanto a denúncia é o 'ato de dar a conhecer crime ou falta alheia', o denuncismo é o 'ato de fazer denúncias sistemáticas, sem base na realidade, apenas para auferir vantagens políticas"' (FIORIN, 2015, p. 79, grifos do autor). Com isso, o autor enfatiza que

Todo discurso constitui-se em oposição a outro discurso. No embate entre eles, constrói-se um simulacro da palavra do outro. Com efeito, não se combate o discurso alheio, mas uma imagem que se cria dele a partir das categorias semânticas do discurso que polemiza com ele. Nessa relação polêmica, certos termos ganham existência para expressar esse simulacro (FIORIN, 2015, p. 79).

Por sua vez, Amossy (2011b, p. 130) informa que é preciso considerar a questão da divergência de pontos de vista, que está na base da argumentação. Para a autora, a argumentação só acontece, de fato, "[...] quando é possível haver uma discordância, ou, no mínimo, uma forma alternativa de ver as coisas". Nesse sentido, ela cita Aristóteles ao afirmar que "[...] não se argumenta sobre o que é evidente". Nessa ótica, a situação argumentativa típica pode ser definida como o desenvolvimento e o confronto de pontos de vistas diferentes sobre uma mesma questão, um mesmo objeto. 
A fim de evitar confusões, Amossy (2011b, p. 131) afirma que é preciso distinguir claramente a intenção da dimensão argumentativa. Para a autora, mesmo que "[...] em sua natureza dialógica o discurso comporte, como qualidade intrínseca, a capacidade de agir sobre o outro, de influenciá-lo", é necessário distinguir "[...] a estratégia de persuasão programada e a tendência de todo discurso a orientar os modos de ver do(s) parceiro(s)". No primeiro caso, o discurso manifesta uma intenção argumentativa (o discurso jurídico, por exemplo). No segundo caso, o discurso comporta simplesmente uma dimensão argumentativa (a notícia de jornal, que se pretende neutra; o relato de uma testemunha sobre algo que viu, por exemplo).

Quando há a intenção de influenciar, de persuadir, o discurso escolhe uma ou mais modalidades argumentativas. Amossy (2011b, p. 131) menciona o uso de três modalidades, a saber: a modalidade demonstrativa, a negociada e a polêmica. $\mathrm{Na}$ primeira modalidade, uma tese é apresentada a um auditório do qual se deseja obter a adesão pelos meios da demonstração fundamentada, do raciocínio articulado apoiado em provas. Na segunda, os parceiros que ocupam posições diferentes esforçam-se para encontrar uma solução comum para o problema e chegar a um acordo. Por fim, na terceira modalidade há um confronto violento de teses opostas, em que duas instâncias em total desacordo buscam superar a convicção da outra, atacando as teses contrárias.

Já no caso da dimensão argumentativa, a estratégia de persuasão acontece de forma indireta, muitas das vezes não admitida, velada. Ou seja, "[e]la aparece na verbalização que produz um discurso cujo objetivo declarado é outro e não o argumentativo: um discurso de informação, uma descrição" (AMOSSY, 2011b, p. 132). Portanto, é preciso identificar e analisar a maneira como esses discursos destinados a, antes de tudo, informar, descrever, testemunhar, direcionam o olhar do outro para fazê-lo perceber as coisas de certa maneira. Indiferentemente de o discurso apresentar ou não uma intenção argumentativa, "[...] a argumentação é inseparável do funcionamento global do discurso" (AMOSSY, 2011b, p. 132), o que significa que o analista deve examiná-la tal como ela se inscreve, concretamente, no discurso, em uma dada situação de comunicação.

\section{Abordagem metodológica e procedimentos de análise}


No que diz respeito à metodologia, nosso estudo assume as características de uma pesquisa qualitativa, descritiva e documental, tendo em vista que busca "[...] descrever/classificar características de uma situação e estabelece conexão entre a base teórico-conceitual existente ou de outros trabalhos já realizados sobre o assunto e os fatos coletados" (CHAROUX, 2004, p. 39). A inserção no âmbito da pesquisa qualitativa apoia-se numa concepção segundo a qual essa abordagem investigativa "[n]ão se apoia na extensão da amostra ou número de informante, mas na riqueza e no detalhamento extraídos destas" (CHAROUX, 2004, p. 38). Deste modo, nessa abordagem, enfatizamos não a quantificação de dados recolhidos, mas a importância das informações que podem ser geradas a partir de um estudo cuidadoso e crítico das fontes documentais.

Para a análise, utilizamos os seguintes procedimentos:

- Leitura atenta dos inquéritos policiais selecionados, com foco em três documentos distintos: o histórico da ocorrência, os termos de depoimentos prestados pela vítima, testemunhas e acusados, e o relatório final elaborado pela delegada.

- Codificação desses inquéritos, caracterizando-os pela natureza das ocorrências. Os documentos foram identificados pelas letras "IP", seguidas de uma numeração crescente: IP01, IP02, IP03 e assim por diante. Para isso, utilizamos as denominações do próprio documento que especifica a natureza da ocorrência, conforme se observa no Quadro 1, logo adiante.

Quadro 1 - Codificação e caracterização dos inquéritos policiais

\begin{tabular}{|c|c|}
\hline Codificação & Natureza da ocorrência \\
\hline IP01 & Ameaça - Lei n 11.340/06 \\
\hline IP02 & Tentativa de estupro - Lei $\mathrm{n}^{\circ} 12.015 / 09$ \\
\hline IP03 & Ameaça de morte - Lei $n^{\circ} 11.340 / 06$ \\
\hline IP04 & Tentativa de homicídio \\
\hline IP05 & Violência doméstica / Agressão física e ameaça \\
\hline IP06 & Lesão corporal - Lei Maria da Penha \\
\hline IP07 & Ameaça / injúria - Lei nº 11.340/06 \\
\hline IP08 & Ameaça e lesão corporal (auto de prisão em flagrante delito) \\
\hline IP09 & Ameaça - Lei nº 11.340/06 \\
\hline
\end{tabular}

Fonte: Dados da pesquisa 
- Transcrição e codificação dos enunciados selecionados para a análise. No caso, selecionamos os enunciados em que ocorrem expressões lexicais que referenciam a mulher na condição de vítima. Esses enunciados receberam a seguinte sinalização: En1, En2, En3 e assim sucessivamente.

- Após esses procedimentos, fizemos um mapeamento para identificarmos a ocorrência das categorias selecionadas para a composição das representações discursivas de vítima: a referenciação, a predicação, a modificação, localização espaço-temporal e a comparação. Nesse momento da análise, o primeiro passo foi identificar e classificar semanticamente os referentes. Em seguida, foram isolados os enunciados com essas ocorrências, com vistas ao trabalho de descrição e interpretação, ao longo da redação do relatório da pesquisa.

\section{As representações discursivas de vítima e a intencionalidade argumentativa}

Nos enunciados a seguir, observamos que, em seu papel temático, o referente "vítima" é designado como paciente das ações descritas nos eventos expressos pelos verbos:

En1/IP01 - "A vítima relata que foi agredida pelos sogros e a cunhada, que residem praticamente no mesmo imóvel, que todos os autores do fato Ihe agrediram todos juntos".

En2/IP01 - "A vítima informa que foi agredida e ameaçada de morte pelo cunhado. Informa também que o mesmo a chamou de rapariga e de cachorra e que iria the quebrar a cara".

Nesses exemplos, o referente "a vítima" é construído no histórico da ocorrência a partir das estruturas predicativas "foi agredida" e "foi agredida e ameaçada de morte". Nesse documento, o referente "a vítima" recebe diferentes modificações por meio dos sintagmas nominais "rapariga" e "cachorra", que, em seu conteúdo semântico, destacam características, nesse caso, negativas, relativas à imagem da vítima. Esses sintagmas, por apresentarem um tom pejorativo, contribuem para construir uma imagem negativa da mulher.

Observemos agora, nos excertos adiante, como a imagem do referente "vítima" é construída na perspectiva das testemunhas. 
En3/IP01 - "A depoente afirma que no dia 26/02/2011, no período da manhã, a vítima e o filho chegaram nervosos e chorando".

En4/IP01 - "Que a vítima estava com um ferimento no braço e na cintura".

En5/IP01 - "Que a vítima [...] foi agredida verbalmente por esta, pelo sogro e a sogra".

En6/IP01 - "Que a depoente também soube por meio da vítima de que esta, desorientada com a situação...".

En7/IP01 - "Que a vítima foi à delegacia para registrar a ocorrência e dormiu na casa de uma amiga porque ficou com medo de que algo lhe acontecesse".

Como se percebe, em destaque, a representação do referente "vítima", a partir do depoimento das testemunhas, compõe-se de expressões modificadoras que desempenham, nos enunciados, funções atributivas e qualificadoras. Esses modificadores contribuem para evidenciar e especificar o estado, tanto físico quanto emocional, do referente: "ferida", "agredida verbalmente", "nervosa”, "desorientada", "com medo".

No entanto, nos depoimentos dos acusados, apresentados nos fragmentos adiante, a representação discursiva do referente "a vítima" é composta pelos modificadores "muito nervosa", "descontrolada", "tão transtornada", "fumaçando" e "parecia endemoniada". Esses modificadores evidenciam e acentuam ainda mais o estado emocional do referente, no sentido de colaborarem para construir uma imagem negativa de "a vítima", ou seja, descrevem a imagem de uma mulher totalmente sem controle de si e da situação.

En9/IP01 - "Que lembra que no dia Pedro estava muito bagunceiro, motivo pelo qual mandou ele entrar em casa e não sair mais, e que a noite chegou a mãe dele, muito nervosa, dizendo que não aguentava mais essa situação, que o filho dela não era saco de pancada".

En10/IP01 - "Que é sogra de Helena [...] percebeu que Helena, descontrolada, ia agredir sua filha, resolveu segurá-la".

En11/IP01 - "Que nunca tinha visto Helena tão transtornada, parecia outra pessoa"

En12/IP01 - "Que é sogro de Helena; que estava no seu comércio, ao lado de sua casa, quando Helena passou para entrar na sua casa".

En13/IP01 - "Que percebeu que Helena estava fumaçando e viu que vinha confusão"

En14/IP01 - "Que Helena parecia endemoniada".

Veja-se que, nos enunciados (En9) "muito nervosa" e (En11) "tão transtornada", os termos "muito" e "tão" intensificam a propriedade dos adjetivos "nervosa" e "transtornada", ressaltando o estado de nervosismo e de transtorno do referente "a vítima". Pode-se inferir que, no depoimento dos acusados, o uso desses 
intensificadores foi empregado de forma intencional, provavelmente para tentarem justificar a agressão praticada contra a vítima, levando a crer que, uma vez que o estado em que ela se encontrava naquele momento precisava ser controlado, a violência física havia sido necessária.

Da mesma forma, no depoimento de um dos acusados (En13, En14), nas predicações "estava fumaçando", "parecia endemoniada", ele [o acusado] utiliza essas expressões metafóricas para caracterizar o estado emocional de "a vítima" por predicação sociocultural negativa e, com isso, também, justificar a ação violenta por ele praticada: "estava fumaçando" (ela estaria tomada de forte ira); "parecia endemoniada" (ela estaria agindo como se estivesse sob uma possessão demoníaca). Nesse segundo caso, o termo "endemoniada" requer do interpretante a ativação de seu conhecimento de mundo, pois a expressão remete a uma palavra bastante utilizada por algumas religiões/seitas, significando aquele que possui sobre si espíritos malignos. Do mesmo modo, o termo "fumaçando" evoca, ainda, em nossa memória discursiva, a imagem de algo destruidor, ameaçador, por estar associado ao fogo (no caso, fora de controle).

No relatório elaborado pela delegada, a representação discursiva de "A vítima" (retomado como "a vítima") é construída, inicialmente, a partir de expressões que a qualificam e a identificam como sendo "nora de", "cunhada de", destacando o grau de parentesco da vítima com os seus agressores. Por sinal, essa representação remete a resultados estatísticos ${ }^{2}$ que revelam que, na maioria das vezes, os casos de violência contra a mulher ocorrem no ambiente familiar.

En15/IP01 - "Consta no presente álbum Inquisitorial, que a vítima é nora de Tereza
dos Santos, Arnaldo dos Santos, e cunhada de Paula Santos".
En16/IP01 - "Que no dia e hora acima citada, a vítima foi agredida fisicamente e
verbalmente por todos os indiciados, a deixando toda machucada."
En17/IP01 - "Temos como meio de prova da prática delitiva, a declaração da vítima,
prova oral acolhida e a cópia do atestado do ITEP de n'xxx da vítima."
En18/IP01 - "Por isto e por tudo que do presente Auto Policial, Peça Informativa
consta e, principalmente em face da concatenação dos fatos trazidos à colação,
resta sobejamente induvidosa a Autoria, inconteste a Materialidade e as
Circunstâncias que ocorreu a conduta Delituosa perpetrada por Paula Santos,
Tereza dos Santos e Arnaldo dos Santos".

\footnotetext{
${ }^{2}$ Dados da pesquisa sobre violência contra a mulher realizada pelo Senado Federal revelaram que $73 \%$ das mulheres vítimas de violência no Brasil têm como seus agressores pessoas do convívio familiar, principalmente o próprio marido, companheiros, ex-companheiros e, por último, pessoas da família. Disponível em: <http://www12.senado.leg.br/senado/procuradoria/publicacao/pesquisaviolencia-domestica-e-familiar-contra-as-mulheres>. Acesso em 12 de mar. 2015.
} 
No relatório do inquérito, a construção da representação do referente "a vítima" deu-se por meio dos processos verbais "foi agredida fisicamente e verbalmente por todos os indiciados" e "a deixando toda machucada". Essas expressões funcionam, no texto do relatório, como uma orientação argumentativa em favor da vítima ("agredida", "toda machucada"), bem como um recurso discursivo indicial, que aponta para os responsáveis pelo delito praticado: "resta sobejamente induvidosa a Autoria, inconteste a Materialidade e as Circunstâncias que ocorreu a conduta Delituosa perpetrada por [...]". O emprego dos sintagmas nominais "sobejamente induvidosa", "inconteste", "conduta delituosa" evidencia a estratégia argumentativa do produtor do texto para alcançar o seu propósito enunciativo: identificar os responsáveis pela agressão praticada contra a vítima.

Por pertencerem ao mesmo campo semântico, as representações discursivas de vítima se conectam a outras representações mais específicas, mais pontuais, conforme podemos observar nos enunciados do Quadro 2, a seguir, em que as representações discursivas da violência são construídas com base nas conexões semânticas que se estabelecem entre as imagens de vítima e as imagens da violência contra a mulher.

Quadro 2 - Representações discursivas da violência

\begin{tabular}{|c|c|}
\hline IP01 & Exemplos \\
\hline En8 & $\begin{array}{l}\text { "Paula começou a agredi-la verbalmente com palavras de baixo calão do } \\
\text { tipo: rapariga" }\end{array}$ \\
\hline En10 & "Que Paula não deixou a vítima falar e começou a gritar." \\
\hline En14 & $\begin{array}{l}\text { "Que Tereza e Arnaldo começaram a empurrar com força a vítima, } \\
\text { encurralando-a no banheiro" }\end{array}$ \\
\hline En18 & $\begin{array}{l}\text { "Que Paula, Tereza e Arnaldo, também, agrediram verbalmente a vítima } \\
\text { com palavras de baixo calão do tipo: "cachorra, satanás, rapariga!" }\end{array}$ \\
\hline En23 & $\begin{array}{l}\text { "Que Marcos a agrediu fisicamente, empurrando duas vezes com força a } \\
\text { vítima" }\end{array}$ \\
\hline En25 & "Que Marcos também ameaçou a vítima" \\
\hline En31 & "Que após o fato, a vítima ficou con \\
\hline IP02 & xemplos \\
\hline
\end{tabular}




\begin{tabular}{|c|c|}
\hline En31 & $\begin{array}{l}\text { "Que ele então disse que queria ter relação sexual: Que a vítima não } \\
\text { aceitou e em razão disso ele iniciou uma discussão passando a agredi-la } \\
\text { [...]". } \\
\text { "Que o INTERROGADO a agrediu com um murro pelo fato da vítima } \\
\text { abandonar a casa para se relacionar com outra pessoa;". }\end{array}$ \\
\hline IP06 & \\
\hline En2 & $\begin{array}{l}\text { "Que quando a vítima entrou na casa do acusado, o mesmo foi logo } \\
\text { fechando a porta, tirou sua blusa e baixou sua roupa íntima. Que o } \\
\text { acusado amarrou as mãos da vítima com uma camisa e tampou sua boca } \\
\text { com uma camisa [...]". }\end{array}$ \\
\hline IP07 & Exemplos \\
\hline En2 & $\begin{array}{l}\text { "Que também era costumeiro ser tratada pelo autor de } \\
\text { insignificante, com desdém, afirmando que sua pessoa não valia n }\end{array}$ \\
\hline En6 & $\begin{array}{l}\text { "Que no dia 25/08/2 } \\
\text { abordada pelo autor }\end{array}$ \\
\hline
\end{tabular}

Nesses enunciados, a violência contra a mulher é representada de diversas formas: agressões verbais com a intenção de manchar a imagem da mulher (En8, En18 do IP01), negação do direito de defesa (En10 do IP01), gritos (En10 do IP01), empurrões (En14 do IP01), agressões físicas (En23 do IP01, En31 do IP02, En6 do IP07), ameaças (En25), medo (En31), ser percebida apenas como objeto de desejo sexual (En1 do IP02), situações de humilhação (En10 do IP07), desprezo (En2 do IP07), difamada por seu companheiro com acusação de ter amante, de abandono do lar (En33 do IP02), tentativa de estupro (En2 do IP06), dentre outras.

\section{Conclusão}

A violência contra a mulher, principalmente na relação conjugal, constitui ainda hoje um espaço de lutas e reivindicações. Denunciar um ato de violência conjugal retira-o do âmbito privado e transforma-o em objeto visível. Diante disso, compreendemos que o estudo das representações discursivas da violência contra a mulher pode trazer sinais de avanços na compreensão desse tipo de violência, posto que esta passa a ser entendida para além dos aspectos físicos, dando ênfase a outros tipos de violência às quais muitas mulheres são submetidas e que, muitas das vezes, não são percebidos como violência. 
Observamos que foram construídas, para o referente "vítima", características específicas, representadas, dentre outras descrições, pelas seguintes expressões linguísticas:

a) no Boletim de ocorrência e no Termo de declarações prestadas pela vítima e pelas testemunhas - "agredida", "ameaçada", "ferida", "nervosa", "chorando", "ofendida moralmente", "encurralada", "machucada", "com medo", "desorientada";

b) no Auto de qualificação e interrogatório dos acusados - "muito nervosa", "descontrolada", "tão transtornada", "fumaçando", "parecia endemoniada", "não queria ter atitudes de casal";

c) no texto do Relatório - "toda machucada", "agredida física e verbalmente", "com o rosto bastante inchado e sangrando", "ameaçada de morte".

Essas representações discursivas, construídas a partir dos pontos de vista de enunciadores diferentes, desempenham as seguintes funções no texto:

a) nas declarações da vítima e das testemunhas - funcionam como um recurso discursivo indicial que aponta para os responsáveis pelo delito praticado, a fim de incriminar o agressor;

b) no relatório - funcionam como um recurso discursivo que orienta para a formação da culpa e a descoberta da autoria do crime;

c) no depoimento dos acusados - funcionam como um recurso discursivo de defesa, na tentativa de justificar a ação delituosa praticada contra a vítima (já que ela [a vítima] "parecia endemoniada", "estava fumaçando").

A análise demonstrou que a violência contra a mulher ultrapassa a violência física, apresentando-se de várias outras formas (ameaças, estupros, maus tratos, atentado ao pudor, agressões verbais, entre outras). Observamos também que um dos principais fatores que contribui para a manutenção das relações violentas é o medo das ameaças, caso a vítima denuncie o agressor.

\section{Referências}

ADAM, Jean-Michel. A linguística textual: introdução à análise textual dos discursos. São Paulo: Cortez, 2011.

AMOSSY, Ruth (org.). Imagens de si no discurso: a construção do ethos. 2 ed. São Paulo: Contexto, 2011a. 
Argumentação e análise do discurso: perspectivas teóricas e recortes disciplinares. Tradução de Eduardo Lopes Pires e Moisés Olimpio Ferreira. EID\&A Revista Eletrônica de Estudos Integrados em Discurso e Argumentação. Ilhéus, n. 1, nov. 2011b, p. 129-144.

BEAUGRANDE, Robert de. New foundations for a science of text and discourse: cognition, communication and freedom of access to knowledge and society. Norwood, New Jersey: Ablex Publishing Corporation, 1997.

CHAROUX, Ofélia Maria Guazzelli. Metodologia: processos de produção, registro e relato do conhecimento. São Paulo: DVS Editora, 2004.

FIORIN, José Luiz. Argumentação. São Paulo: Contexto, 2015.

KOCH, Ingedore G. Villaça. Argumentação e linguagem. 13. ed. São Paulo: Cortez, 2011.

. A inter-ação pela linguagem. 10. ed. São Paulo: Contexto, 2010.

OLIVEIRA, Marcela Beraldo de. Da Delegacia de Defesa da Mulher ao Juizado Especial Criminal: significados da violência de gênero no fluxo processual. 2004. Disponível em: <http://www.pagu.unicamp.br/sites/www.pagu.unicamp.br/files/colenc.05.a02.pdf>. Acesso em 12 jun. 2012.

PASINATO, Wânia. Justiça para todos: os Juizados Especiais Criminais e a violência de gênero. 376f. Tese (Doutorado em Sociologia) USP. São Paulo, 2003.

QUEIROZ, Fernanda Marques de. Não se rima amor e dor. cenas cotidianas de violência contra a mulher. Mossoró, RN: UERN, 2008.

RAMOS, Milton Guilherme. Representações discursivas de ficar e namorar em textos de vestibulandos e pré-vestibulandos. 2011. Tese (Doutorado em Linguística Aplicada) - Universidade Federal do Rio Grande do Norte, PPGEL, Natal, 2011.

RODRIGUES, Maria das Graças Soares; PASSEGUI, Luis; SILVA NETO, João Gomes da. (Orgs.) "Voltarei. O povo me absolverá...": a construção de um discurso político de renúncia. In.: ADAM, Jean-Michel; HEIDMANN, Ute; MAINGUENEAU, Dominique. Análises textuais e discursivas: metodologia e aplicações. São Paulo: Cortez, 2010, p. 150-195. 